\title{
Multi-objective Optimization of Condensation Heat Transfer inside Horizontal Tube using Particle Swarm Optimization Technique
}

\author{
Ravindra Kumar ${ }^{\text {a* }}$, P. Kumar ${ }^{\mathrm{b}}$ \\ $\mathrm{a}^{*}$ Research Scholar, Department of Mechanical Engineering, \\ National Institute of Technology, Jharkhand, India \\ kumarravindramahto@gmail.com \\ ${ }^{\mathrm{b}}$ Associate Professor, Department of Mechanical Engineering, \\ National Institute of Technology, Jharkhand, India \\ pkshmdme@gmail.com
}

\begin{abstract}
In this paper, heat transfer coefficient and frictional pressure drop during condensation of refrigerant inside a smooth tube are formulated as a multi - optimization problem and solved using particle swarm optimization (PSO) algorithm. The objective of this work is to predict the optimum values of refrigerant mass flux and vapor quality for which there is a maximum condensation heat transfer and minimum flow frictional pressure gradient inside tube. The PSO algorithm was run for mass flux and vapor quality range from $100 \mathrm{~kg} / \mathrm{m}^{2}$-s to $250 \mathrm{~kg} / \mathrm{m}^{2}$-s and 0.1 to 0.8 respectively. The optimum refrigerant mass flux and vapor quality predicted by particle swarm optimization algorithm are $134.85 \mathrm{~kg} / \mathrm{m}^{2}$-s and 0.79 respectively.
\end{abstract}

Keyword- Condensation, Frictional pressure gradient, Heat transfer coefficient, Particle swarm optimization

\section{INTRODUCTION}

Over the years, a number of experimental works have been done on condensation heat transfer and pressure drop for different refrigerants and tube geometries. The effect of design and operating parameters on heat transfer coefficient and pressure has been investigated by researchers. Heat transfer coefficient and pressure drop were determined using several empirical correlations. A little attention has been given on the optimization of heat transfer and pressure drop during the condensation of the refrigerant inside plain tube.

The heat transfer coefficient and pressure drop depend on many factors such as mass flux, vapour quality and properties of refrigerant, tube's geometry and orientation. The heat transfer coefficient and pressure drop are found to increase with the increasing mass flux and vapor quality of refrigerant. The condensation heat transfer inside tube is accomplished by pump work. The pump work is found to increase with pressure drop along the tube during condensation. The design and operating parameters are required to be optimized to achieve maximum heat transfer and minimum pressure drop.

Existing literature reveals that many researchers have used different optimization methods for the design optimization of heat exchangers. Artificial neural network (ANN) and genetic algorithm (GA) used to develop the empirical correlations for heat transfer characteristics during the downward flow of R-134a inside smooth and corrugated tubes [1,2]. Heat transfer rate and pressure drop in shell and tube heat exchanger was optimized using genetic algorithm [3]. Genetic and particle swarm optimization (PSO) algorithms were employed for thermo economic optimization of shell and tube condenser [4]. Teaching-learning based optimization (TLBO) technique was used to optimize the cost, weight, effective of plate fin heat exchanger [5]. Effectiveness and cost optimization of the plate fin exchanger was performed using modified teaching-learning based optimization technique [6]. Heat transfer coefficient optimization during condensation of refrigerant inside smooth horizontal tube was done through TLBO [7].

The objective of the present paper is to predict the optimum value of refrigerant mass flux and vapor quality for which there is maximum heat transfer coefficient and minimum pressure drop during the condensation of R$245 \mathrm{fa}$ inside the plain horizontal tube using particle swarm optimization method. 


\section{PARTICLE SWARM OPTIMIZATION TECHNIUQE (PSO)}

Particle swarm optimization (PSO) is a population based evolutionary optimization method proposed by Kennedy [8]. Figure 1 shows the flow chart of PSO. In particle swarm optimization algorithm the population is randomly initialized and moves in randomly selected directions through the search space and keeps record of the best previous position of itself and its neighbors as well. The population updates after each generation based on the best location achieved by a particle, Pbest, and other best location achieved by any other particle among the population, gbest, so far.

In particle swarm optimization the population is updated after each generation by changing the velocity and position of each particle towards Pbest and gbest. The velocity and position are updated according to equations 1 and 2 .

$$
\begin{gathered}
\mathrm{v}_{\mathrm{i}}^{\mathrm{t}+1}=\mathrm{WV}_{\mathrm{i}}^{\mathrm{t}}+\mathrm{c}_{1} \text { rand }_{1}\left[\text { gbest }_{i}^{\mathrm{t}}-\mathrm{x}_{\mathrm{i}}^{\mathrm{t}}\right]+\mathrm{c}_{2} \operatorname{rand}_{2}\left[\text { gbest }_{\mathrm{i}}^{\mathrm{t}}-\mathrm{x}_{\mathrm{i}}^{\mathrm{t}}\right](1) \\
x_{1}^{\mathrm{t}+1}=\mathrm{x}_{\mathrm{i}}^{\mathrm{t}}+\mathrm{v}_{\mathrm{i}}^{\mathrm{t}+1}(2)
\end{gathered}
$$

Where, $\mathrm{i}=$ population index

$\mathrm{t}=$ generation

$x_{\mathrm{i}}^{\mathrm{t}}=$ position of $\mathrm{i}^{\text {th }}$ particle.

$v_{\mathrm{i}}^{\mathrm{t}}=$ velocity of $\mathrm{i}^{\text {th }}$ particle.

Pbest $_{i}{ }^{t}=$ best previous position of particle.

gbest $_{i}{ }^{t}=$ the best particle among all particles in a swarm.

$\operatorname{rand}_{1}$, rand $_{2}$ are two different random numbers in the range [0 1]

Local and global search is balanced by inertia weight ' $w$ '. The high inertia weights permit travelling the large design space while small inertia weights permit travelling only nearby region of the design space by particles. The value of inertia weights is considered in the range [0.4 0.9]. The optimum value of inertia weights improves the performance of the algorithm. The acceleration coefficients $c_{1}$ and $c_{2}$ are recognized as cognitive and social parameters. The cognitive and social parameters pull each particle towards Pbest and gbest respectively. Small value of constants allows particles to travel far away from the target regions before being pulled back, while high value of constants results in sudden movement towards the target region [9]. Bergh F and Engelbrecht [10] have reported effect of $\mathrm{c}_{1}, \mathrm{c}_{2}$, and $\mathrm{w}$, on various standard functions. In the present paper, particle swarm optimization algorithm was run considering the following parameters:

Number of particles $=50$

Number if iteration $=100$

Cognitive parameter $\left(\mathrm{c}_{1}\right)=2$

Social parameter $\left(\mathrm{c}_{2}\right)=2$

Inertia weights range [0.9 0.4$]$

\section{PROBLEM FORMULATION FOR MULTI OBJECTIVE OPTIMIZATION}

For optimum performance of the condenser, the heat transfer coefficient and pressure drop along the flow are required to be optimized. Multi-objective optimization of maximization and minimization functions together can be done considering a single objective function, as represented by Eq. 3 .

$$
\operatorname{maxf}(\mathrm{z})=\frac{\omega \times \mathrm{f}_{1}(\mathrm{z})}{\mathrm{f}_{1}^{*}}-\frac{(1-\omega) \times \mathrm{f}_{2}(\mathrm{z})}{\mathrm{f}_{2}^{*}}(3)
$$

Where, combined objective function $\mathrm{f}(\mathrm{z})$ is a function of two functions $f_{1}(z)$ and $f_{2}(z)$ to bemaximized and minimized respectively. $f_{1}^{*}, f_{2}^{*}$ are the maximum and minimum values of $f_{1}(z)$ and $f_{2}(z)$ when solved, as a single objective problem separately. Here $\omega$ is the weight assigned to objective functions. 


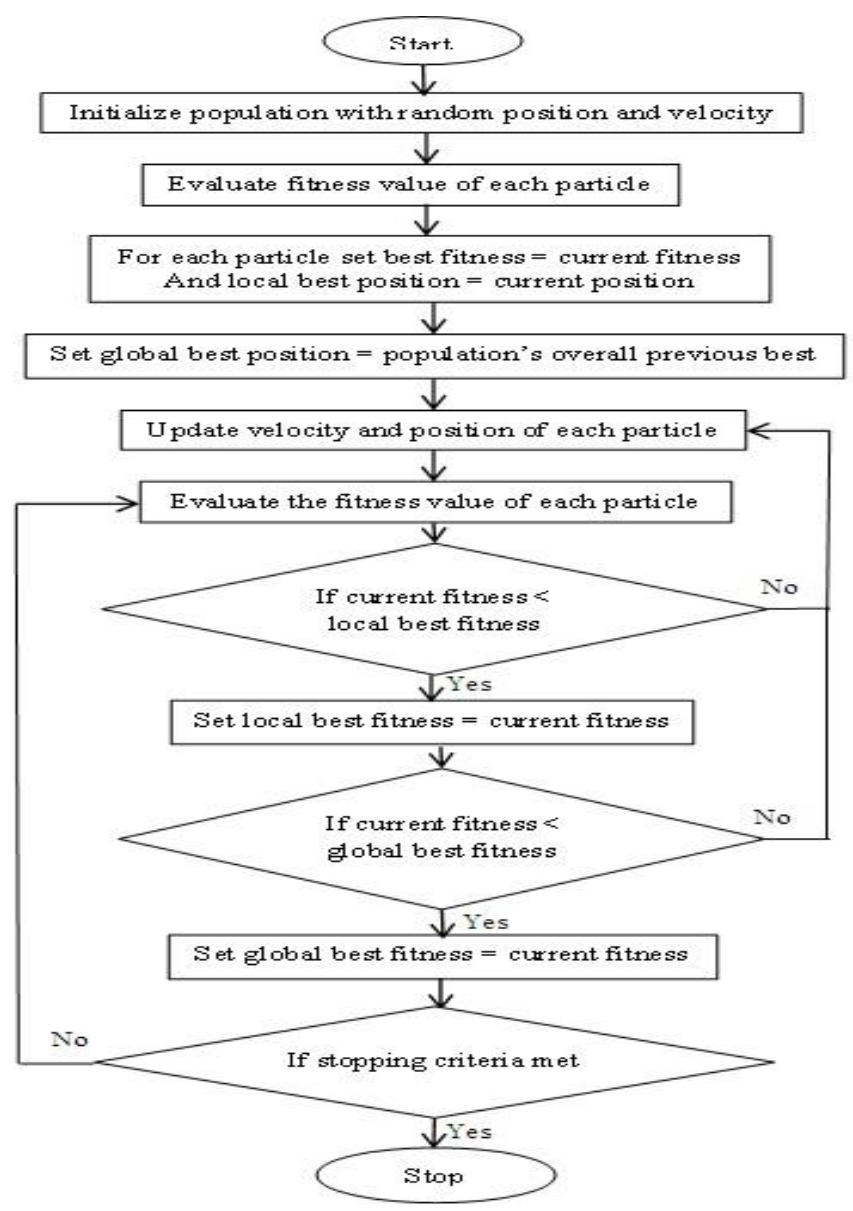

Fig. 1. Flow chart of particle swarm optimization algorithm.

\section{EXPERIMENTAL SYSTEM}

The particle swarm optimization algorithm results were validated with experimental data obtained from the experimental system shown in Figure 2. The experimental system is a concentric double pipe heat exchanger having two test sections of length one meter each. The inner and outer diameters of inner tube are $9.4 \mathrm{~mm}, 12.76$ mmand that of the outer tube are $43 \mathrm{~mm}, 50 \mathrm{~mm}$. The experiments were carried out according to the parameters shown in Table 1. A multichannel data acquisition system was incorporated with experimental system for data recording. R-245fa vapor and cooling water were flown in counter direction through the inner and outer tubes inside the test sections. The refrigerant vapor coming from the test section 2 flows through the post condenser where the entire amount of refrigerant vapour converted into liquid. This entire liquid refrigerant flows through the evaporator, made of stainless steel tube having inside diameter, outside diameter and length $16 \mathrm{~mm}, 17.5$ $\mathrm{mm}$ and $3.6 \mathrm{~m}$ respectively. A step-down transformer incorporated with evaporator controls the vapor quality of refrigerant. A corioles mass flow meter was connected to control the refrigerant mass flow rate. Four T-type thermocouples were fixed at each six axial locations to quantity the accurate temperature of outer wall of the inner tube. The refrigerant pressure at the inlet and outlet of each test section was measured by pressure gauge. The pressure difference across the test section was measured using a pressure transducer. Condenser pressure was taken as the average refrigerant pressure of both test sections. Refrigerant properties were taken according to average condenser pressure. 


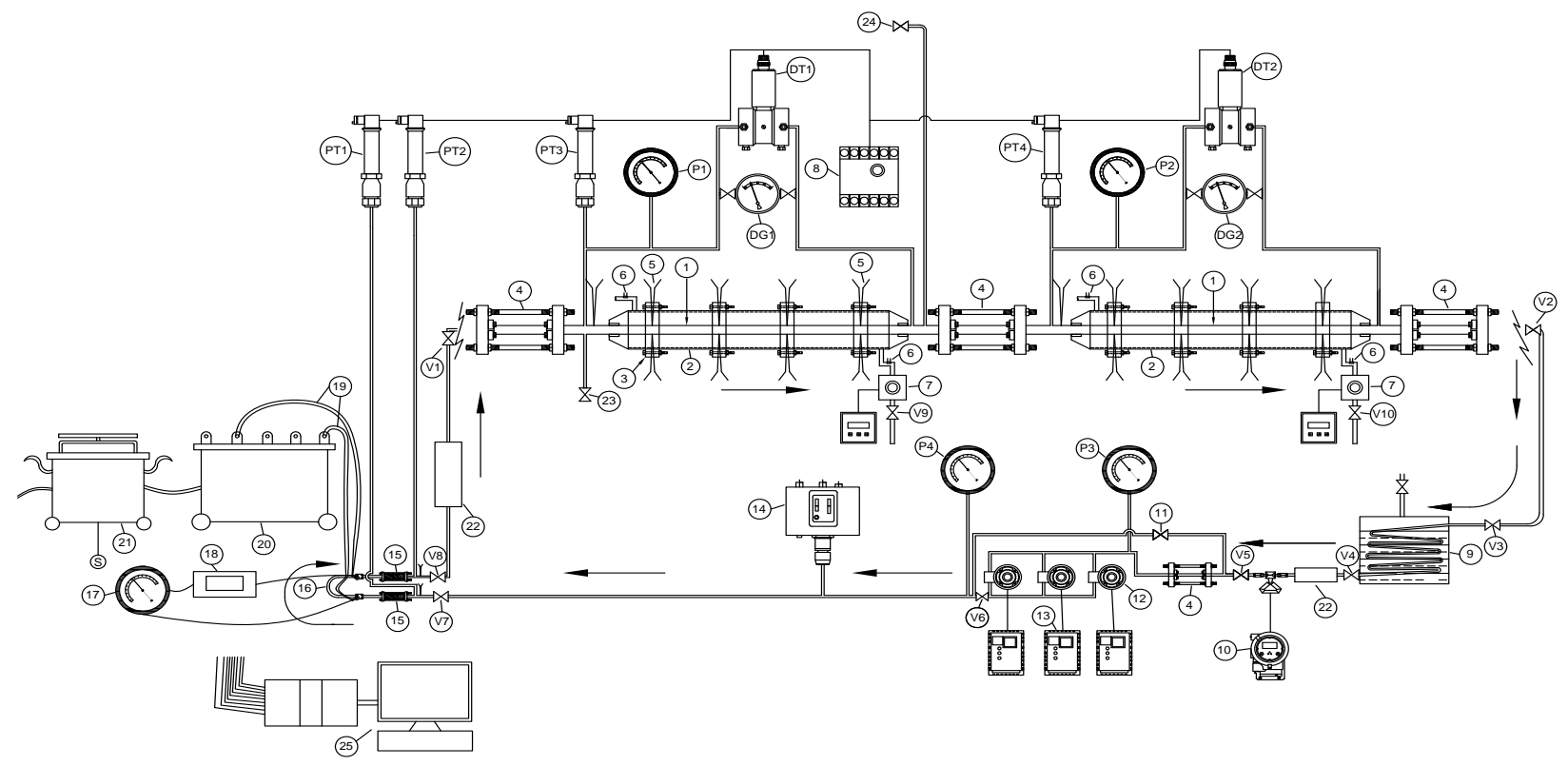

Fig. 2. Schematic diagram of experimental system.

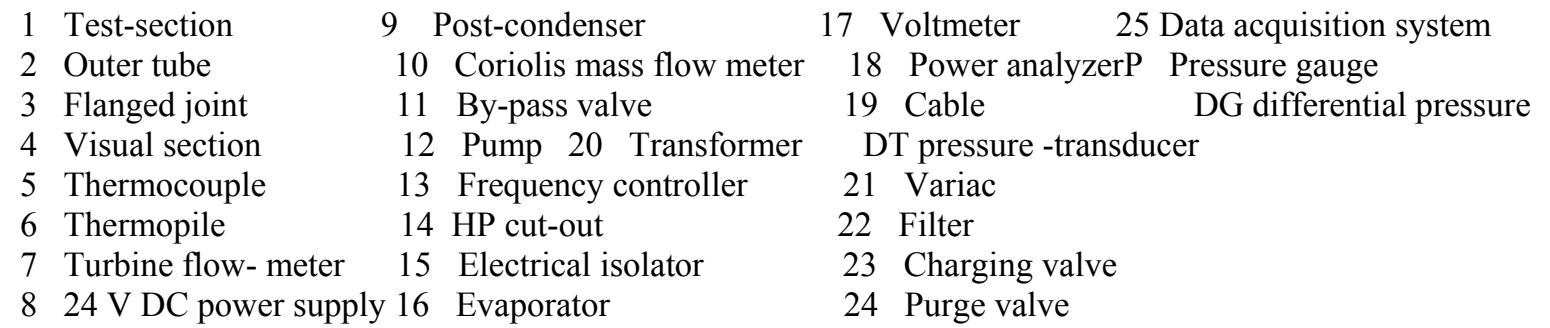

Table 1. Operating parameters

\begin{tabular}{|c|c|}
\hline Parameters & Value \\
\hline Refrigerant mass flux $\left(\mathrm{kg} / \mathrm{m}^{2} \mathrm{~s}\right)$ & $100-250$ \\
\hline Heat flux $\left(\mathrm{kW} / \mathrm{m}^{2}\right)$ & $7.5-20.5$ \\
\hline Condensing pressure $(\mathrm{kPa})$ & 220 \\
\hline Condensing temperature $\left({ }^{0} \mathrm{C}\right)$ & 35.95 \\
\hline Vapor quality & $0.1-0.8$ \\
\hline
\end{tabular}

\section{DATA COLLECTION AND DATA REDUCTION}

The experimentation was carryout for the condensation of R-245fa with refrigerant mass fluxes 100, 150,200 and $250 \mathrm{~kg} / \mathrm{m}^{2}$-s and vapor quality range from 0.1 to 0.8 . The vapor quality at entry and exit of each test section was calculated through energy balance along the test condenser and evaporator. The test section vapor quality was considered as the average of its entry and exit values.

The heat transfer coefficient of each test section was calculated by applying energy balance between refrigerant vapor and water using Eq. 4. The overall heat transfer coefficient for each test run was considered as the average of two test sections.

$\mathrm{h}=\left[\frac{\Pi \mathrm{D}_{\mathrm{i}} 1\left(\mathrm{~T}_{\mathrm{s}}-\mathrm{T}_{\mathrm{wo}}\right)}{\mathrm{m}_{\mathrm{w}} \mathrm{C}_{\mathrm{pw}}\left(\mathrm{T}_{\mathrm{c}, \mathrm{o}}-\mathrm{T}_{\mathrm{c}, \mathrm{in}}\right)}-\frac{\mathrm{D}_{\mathrm{i}} \ln \left(\mathrm{D}_{\mathrm{o}} / \mathrm{D}_{\mathrm{i}}\right)}{2 \mathrm{k}_{\mathrm{w}}}\right]^{-1}(4)$

The two phase flow frictional pressure drop during condensation of R-245fa inside a plain horizontal tube was calculated by Eq. 5 .

$\Delta \mathrm{P}_{\text {fri }}=\Delta \mathrm{P}_{\text {tot }}-\Delta \mathrm{P}_{\mathrm{mom}}$

Where $\Delta \mathrm{P}_{\text {fri }}, \Delta \mathrm{P}_{\text {tot }}$ and $\Delta \mathrm{P}_{\text {nom }}$ are frictional pressure drop, total pressure drop measured by pressure gauge and momentum pressure drop respectively. The calculation of the momentum pressure drop was made according to Eq.6. 
$\Delta P_{\text {mom }}=G^{2}\left\{\left[\frac{(1-x)^{2}}{\rho_{\mathrm{L}}(1-\alpha)}+\frac{\mathrm{x}^{2}}{\rho_{\mathrm{G}} \alpha}\right]_{\text {out }}-\left[\frac{(1-\mathrm{x})^{2}}{\rho_{\mathrm{L}}(1-\alpha)}+\frac{\mathrm{x}^{2}}{\rho_{\mathrm{G}} \alpha}\right]_{\mathrm{in}}\right\}(6)$

Here ' $\alpha$ ' is the void fraction calculated as suggested by Steiner.

\section{RESULTS AND DISCUSSION}

\section{A. Heat transfer coefficient}

Figure 3 represents the effect of refrigerant mass flux and vapor quality on the heat transfer coefficient during condensation of R-245fa inside a plain horizontal tube. As could be seen from the figure, heat transfer coefficient increases with rise in vapor quality and mass flux. The maximum heat transfer coefficient $3.27 \mathrm{~kW} / \mathrm{m}^{2} \mathrm{~K}$ was reported at mass flux $250 \mathrm{~kg} / \mathrm{m}^{2} \mathrm{~s}$ and vapor quality 0.8 . The rise in heat transfer coefficient is due to high turbulence induced in the condensate film at high mass flux and low thermal resistance offered to condensation heat transfer coefficient by thin vapor film on tube wall at high vapour quality $[11,12]$. Experimental data of heat transfer coefficient were compared with several well-known correlations to predict the heat transfer coefficient during condensation of R-245fa inside a smooth horizontal tube. The Dobson's correlation [13] predicted the present heat transfer coefficient data within an error range of $\pm 20 \%$ as shown in Figure 4. The Dobson's correlation of heat transfer coefficient for plain flow inside a horizontal tube is given by Eq. 7.

$\mathrm{h}=0.023 \times \operatorname{Re}^{0.8} \times \operatorname{Pr}^{0.4} \times\left[\frac{\mathrm{k}}{\mathrm{D}_{\mathrm{i}}}\right] \times\left[1+\frac{2.22}{\mathrm{X}_{\mathrm{tt}}^{0.89}}\right](7)$

Where $\mathrm{Xtt}$ is known Martinelli parameter computed as according to equation 8.

$\mathrm{X}_{\mathrm{tt}}=\left(\frac{1-\mathrm{x}}{\mathrm{X}}\right)^{0.9}\left(\frac{\rho_{\mathrm{G}}}{\rho_{\mathrm{L}}}\right)^{0.5}\left(\frac{\mu_{\mathrm{L}}}{\mu_{\mathrm{G}}}\right)^{0.1}$

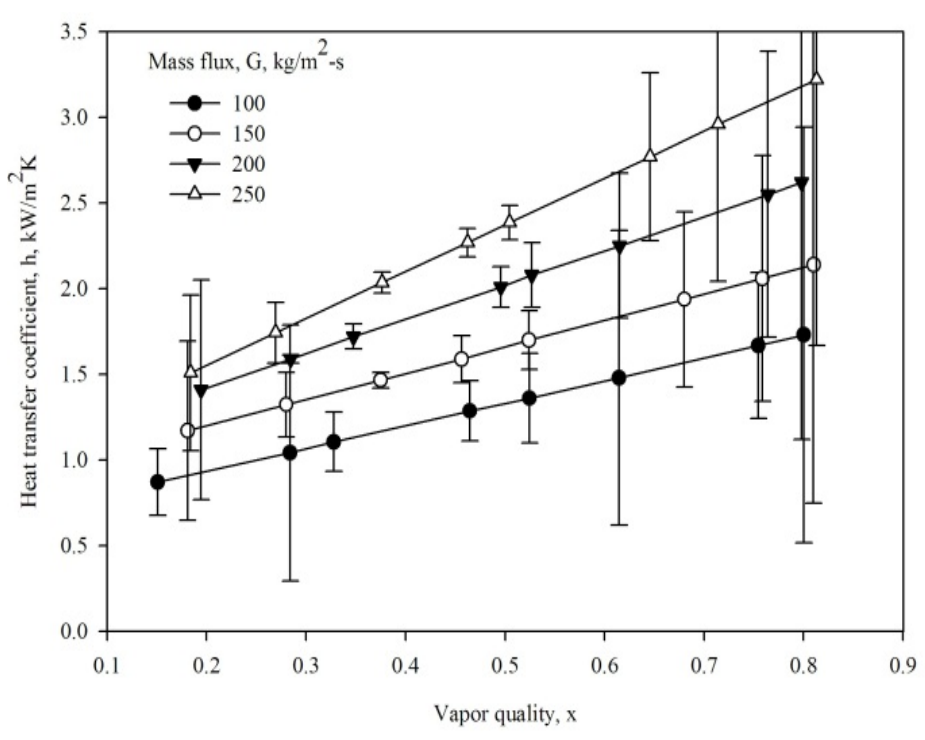

Fig. 3. Effect of mass flux and vapor quality on the heat transfer coefficient. 


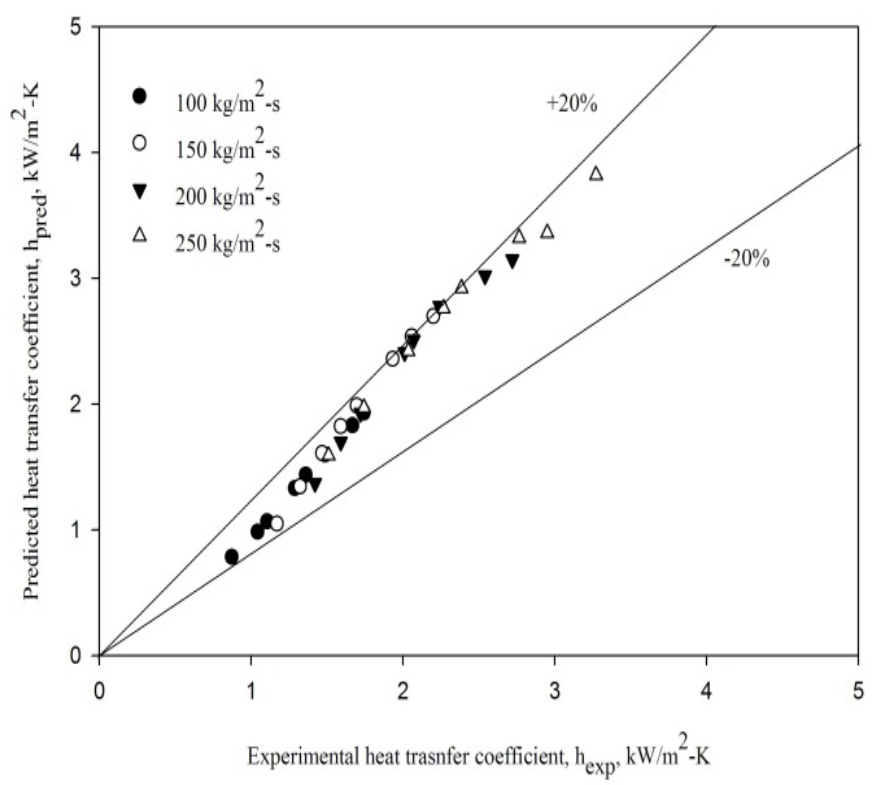

Fig. 4. Comparison of experimental heat transfer coefficient with that predicted by Dobson's correlation.

\section{B. Frictional pressure drop}

Figure 5 shows the effect of refrigerant mass flux and vapor quality on the frictional pressure drop along the flow during condensation of R-245fa inside aplain horizontal tube. As could be seen from the figure, frictional pressure drop increases with mass flux and vapor quality of refrigerant. Increasing mass flux produces greater two-phase velocity resulting in a greater frictional pressure drop. This effect is more evident in the high vapor quality region where the pattern changes into fully developed annular region flow. The increase in frictional pressure drop with vapor quality at any mass flux is due to changes in flow pattern with increasing vapor quality.

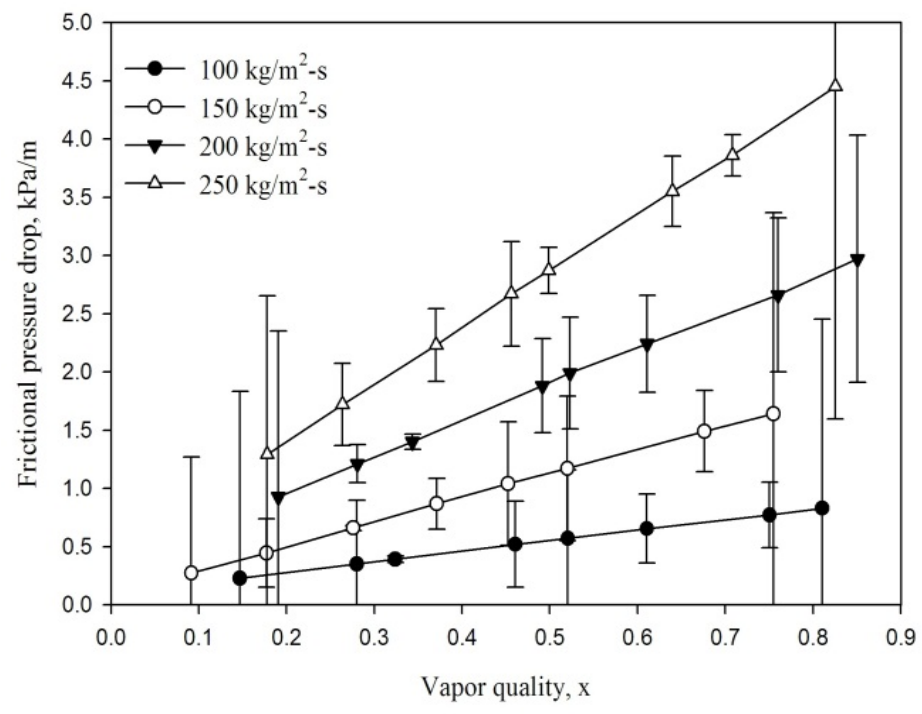

Fig. 5. Variation in frictional pressure drop with mass flux and vapor quality.

The present frictional pressure drop data were compared with some well-known two phase flow frictional pressure drop correlations $[14,15,16]$. Fig. 6 represents the comparison of experimental frictional pressure drop with that of predicted by above mentioned correlations. As could be observed from the figure all correlations predicted the data beyond an error range of $+15 \%$. 


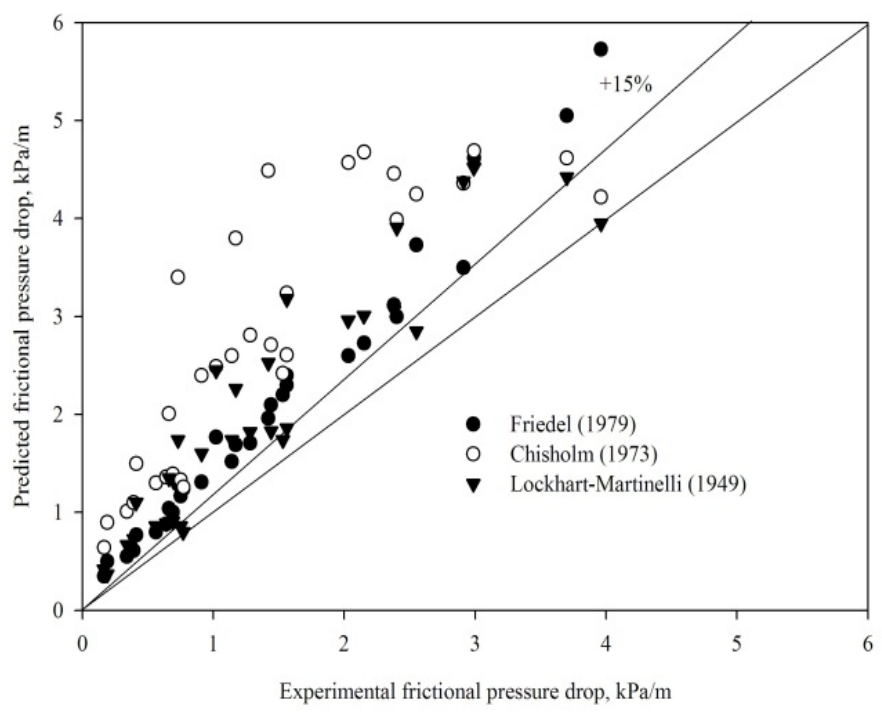

Fig. 6. Comparison of experimental frictional with different correlations.

The present experimental data were used to develop an empirical correlation based on Cavallini [17] to predict frictional pressure drop during condensation of R-245fa inside plain horizontal tube. The Eq. 9 is the modified correlation of frictional pressure drop for condensation inside a smooth horizontal tube. The experimental data predicted by Eq. 9 are within an error band of $-5 \%$ to $+15 \%$, as shown in Figure 7 .

$\left(\frac{\mathrm{dp}}{\mathrm{dz}}\right)_{\mathrm{f}}=\varphi_{\mathrm{LO}}^{2} \times 2 \times \mathrm{f}_{\mathrm{LO}} \times \frac{\mathrm{G}^{2}}{\mathrm{D}_{\mathrm{i}} \times \rho_{\mathrm{L}}}$

Where,

$\mathrm{f}_{\mathrm{LO}}=0.034 \times\left(\frac{\mathrm{G} \times \mathrm{D}_{i}}{\mu_{1}}\right)^{-0.25}(10)$
$\varphi^{2}{ }_{L O}=\mathrm{Z}+3.595 \times \mathrm{F} \times \mathrm{H}(11)$
$\mathrm{Z}=(1-\mathrm{x})^{2}+\mathrm{x}^{2} \times\left(\frac{\rho_{\mathrm{L}}}{\rho_{\mathrm{G}}}\right) \times\left(\frac{\mu_{\mathrm{G}}}{\mu_{\mathrm{L}}}\right)^{0.2}(12)$
$\mathrm{F}=\mathrm{x}^{0.9525} \times(1-\mathrm{x})^{0.414}(13)$
$\mathrm{H}=\left(\frac{\rho_{\mathrm{L}}}{\rho_{\mathrm{G}}}\right)^{1.132} \times\left(\frac{\mu_{\mathrm{G}}}{\mu_{\mathrm{L}}}\right)^{0.44} \times\left(1-\frac{\mu_{\mathrm{G}}}{\mu_{\mathrm{L}}}\right)^{3.542}$

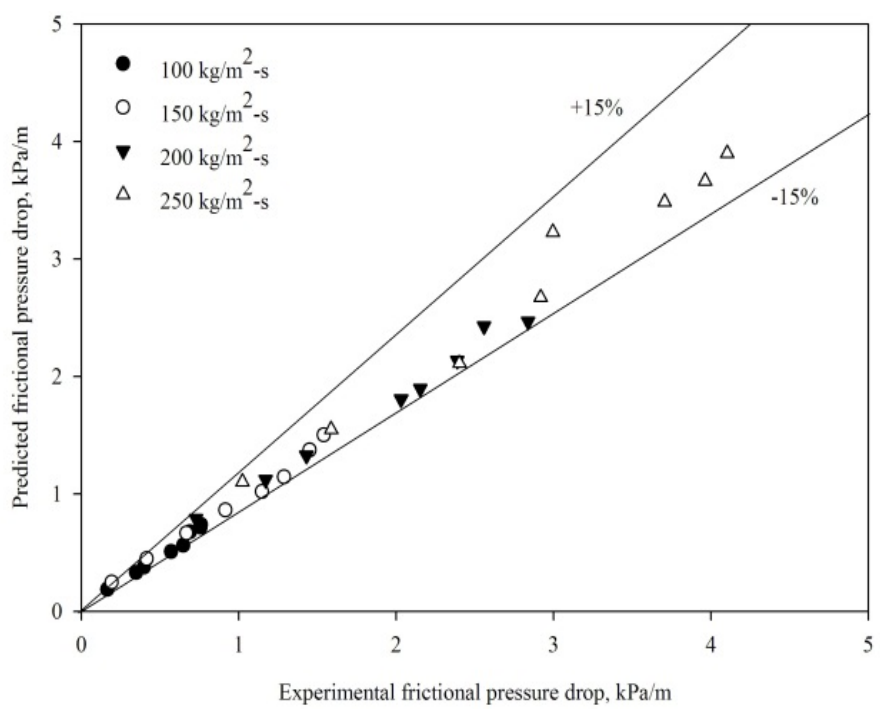

Fig. 7. Comparison of experimental frictional pressure drop with that predicted by Eq. 9 


\section{Validation of particle swarm optimization algorithm (PSO)}

The particle swarm optimization algorithm was executed for the maximization of heat transfer coefficient during condensation of R-245fa inside a smooth horizontal tube. The Eq. 7 was considered as a maximization objective function. The algorithm was run initially executed at each mass flux 100, 150, 200, and $250 \mathrm{~kg} / \mathrm{m}^{2} \mathrm{~s}$. Vapor quality of refrigerant was varied from 0.1 to 0.8 for each mass flux. The optimized results were compared with experimental, as shown in Table 2. The PSO algorithm was again run for the same maximization function with mass flux and vapor quality varying between 100 to $250 \mathrm{~kg} / \mathrm{m}^{2} \mathrm{~s}$ and 0.1 to 0.8 respectively. Table 3 shows the comparison of PSO predicted and experimental. As could be observed from tables 3 and 4, PSO predicted values are very close to the experimental.

Table 2. Comparison between PSO and experimental results.

\begin{tabular}{|c|c|c|c|c|}
\hline \multirow{2}{*}{$\begin{array}{c}\text { Mass flux } \\
\left(\mathrm{kg} / \mathrm{m}^{2} \mathrm{~s}\right)\end{array}$} & \multicolumn{2}{|c|}{ Vapour quality } & \multicolumn{2}{c|}{ Heat transfer coefficient $\left(\mathrm{kW} / \mathrm{m}^{2} \mathrm{~K}\right)$} \\
\cline { 2 - 5 } & Experimental & PSO & Experimental & PSO \\
\hline 100 & 0.8 & 0.792 & 1.75 & 1.89 \\
\hline 150 & 0.8 & 0.797 & 2.15 & 2.42 \\
\hline 200 & 0.8 & 0.785 & 2.54 & 2.92 \\
\hline 250 & 0.8 & 0.796 & 3.27 & 3.66 \\
\hline
\end{tabular}

Table 3. Comparison of optimized results

\begin{tabular}{|c|c|c|}
\hline Parameters & Experimental & PSO \\
\hline Mass flux of R-245fa $\left(\mathrm{kg} / \mathrm{m}^{2} \mathrm{~s}\right)$ & 250 & 248.21 \\
\hline Vapor quality & 0.8 & 0.775 \\
\hline Optimum heat transfer coefficient $\left(\mathrm{kW} / \mathrm{m}^{2} \mathrm{~K}\right)$ & 3.27 & 3.75 \\
\hline
\end{tabular}

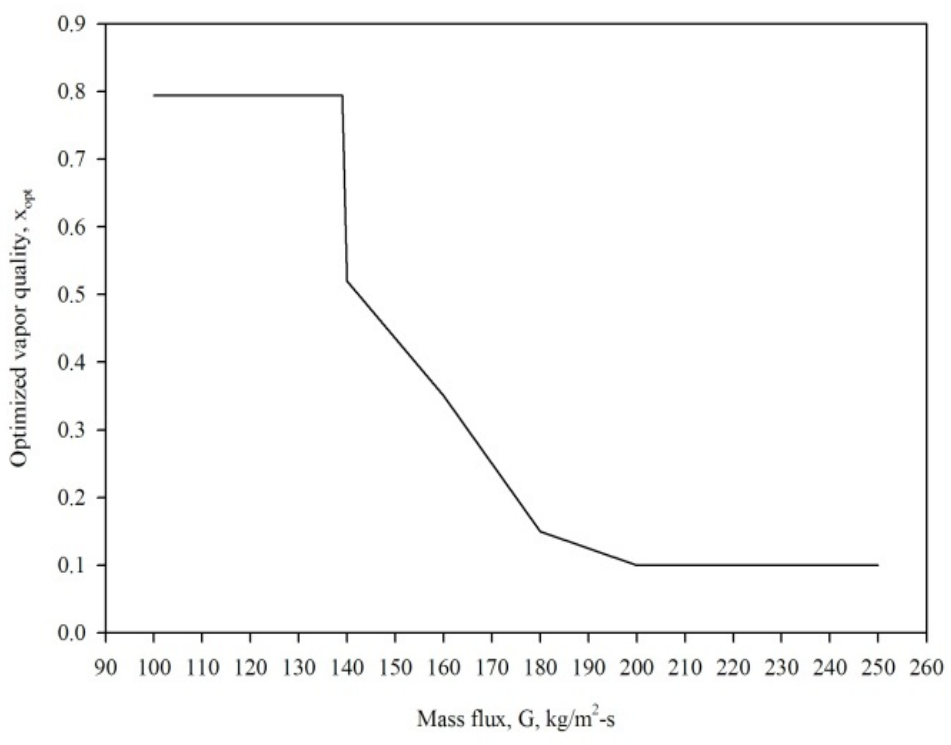

Fig. 8. Variation in optimum vapor quality with mass flux.

\section{Optimization of heat transfer coefficient and frictional pressure drop}

A single multi-objective optimization problem was formulated as according to Eq. 3 for the maximization of heat transfer coefficient and minimization of fractional pressure drop. The PSO algorithm was initially for multi-objective optimization problem at constant refrigerant mass flux between $100 \mathrm{~kg} / \mathrm{m}^{2} \mathrm{~s}$ to $250 \mathrm{~kg} / \mathrm{m}^{2} \mathrm{~s}$ with step size 1 and vapor quality was varied from 0.1 to 0.8 for each mass flux. Fig. 8 represents the optimized refrigerant vapor quality for each mass flux. As could be seen, up to the mass flux $139 \mathrm{~kg} / \mathrm{m}^{2} \mathrm{~s}$ optimized vapor quality predicted by PSO is 0.794 . And as the mass flux increased beyond $139 \mathrm{~kg} / \mathrm{m}^{2} \mathrm{~s}$ optimized vapor quality went on decreasing and became constant $(0.1)$ on and after $200 \mathrm{~kg} / \mathrm{m}^{2} \mathrm{~s}$. The algorithm was run again considering the mass flux and vapour quality as variables. The mass flux and vapour quality were varied from 
100 to $250 \mathrm{~kg} / \mathrm{m}^{2} \mathrm{~s}$ and 0.1 to 0.8 respectively. The optimum refrigerant mass flux and vapor quality predicted by PSO was $134.85 \mathrm{~kg} / \mathrm{m}^{2}$-s and 0.79 respectively.

\section{CONCLUSIONS}

On the basis of above results following inferences may be drawn pertaining to the condensation heat transfer and frictional pressure drop during condensation of R-245fa inside a smooth horizontal tube and their optimization using particle swarm optimization technique.

1. Refrigerant mass flux and vapor quality have greater influence on the heat transfer coefficient and frictional pressure drop during condensation. Heat transfer coefficient and frictional pressure drop along the flow inside tube increase with increasing mass flux and vapor quality.

2. The particle swarm optimization technique was effectively applied to multi-objective optimization of heat transfer coefficient and frictional pressure drop. Refrigerant mass flux below $140 \mathrm{~kg} / \mathrm{m}^{2} \mathrm{~s}$ can provide maximum heat transfer and minimum pressured drop during condensation inside plain tubes. The values of optimum mass flux and vapor quality predicted by particle swarm optimization are $134.85 \mathrm{~kg} / \mathrm{m}^{2} \mathrm{~s}$ and 0.79 respectively.

3. The particle swarm optimization algorithm may also be used for the multi-objective optimization of design and operating parameters during swirling flow condensation of refrigerants inside tubes.

\section{LIST OF SYMBLOS}

\section{$\mathrm{C}_{\mathrm{P}}$ Specific heat $(\mathrm{kJ} / \mathrm{kg} \mathrm{K})$}

DTube diameter $(\mathrm{mm})$

G Mass flux $\left(\mathrm{kg} / \mathrm{m}^{2} . \mathrm{s}\right)$

h Heat transfer coefficient $\left(\mathrm{kW} / \mathrm{m}^{2} \mathrm{~K}\right)$

kThermal conductivity (W / m K)

$\mathrm{x} \quad$ Vapor quality

$\mu$ Viscosity ( $\mu \mathrm{Pa}-\mathrm{s})$

$\rho$ Density $\left(\mathrm{kg} / \mathrm{m}^{3}\right)$

Re Reynolds number

Pr Prandtl number

Xtt Martinelli parameter

\section{DIMENSIONLESS NUMBERS}

$\begin{array}{ll}\text { L } & \text { liquid } \\ \text { G } & \text { gas } \\ \text { LO } & \text { liquid only } \\ \text { B } & \text { bottom } \\ \text { R } & \text { right } \\ \text { i } & \text { inner } \\ \text { o } & \text { outer }\end{array}$

\section{SUBSCRIPT}

\section{REFERENCES}

[1] M. Balcilar et al., "Investigation of empirical correlation on the determination of condensation heat transfer characteristics during downward annular flow of R-134a inside a vertical smooth tube using artificial intelligence algorithm", Journal of Mechanical Science and Technology, Vol.25, pp. $2683-2701,2011$.

[2] M. Balcilar et al., "A numerical correlation development study for the determination of Nusselt number during boiling and condensation of R-134a inside smooth and corrugated tube", International Communication in Heat and Mass Transfer, Vol. 48, pp. $141-148,2013$.

[3] S. Sepher, H Hajabdollahi, "Multi-objective optimization of shell and tube heat exchanger", Applied Thermal Engineering, Vol. 30, pp. $1937-1945,2010$.

[4] P. Ahmadi et al., "Thermo economic optimization of a shell and tube condenser using both genetic algorithm and particle swarm optimization technique", International journal of refrigeration, Vol. 34, pp. 1066 - 1076, 2011.

[5] V. Patel, V. Savsani ,"Optimization of a plate-fin heat exchanger design through an improved multi-objective teaching-learning based optimization algorithm”, Chemical Engineering Research and Design, Vol. 92, pp. 2371-82, 2014

[6] R.V. Rao, V. Patel, "Multi-objective optimization of heat exchangers using a modified teaching-learning based optimization algorithm”, Applied Mathematical Modeling, Vol. 37, pp. 1147-1162, 2013.

[7] Ravindra Kumar, P. Kumar, "Optimization of heat transfer coefficient during condensation of refrigerant inside plain horizontal tube using teaching-learning based optimization algorithm", Indian journal of science and technology, Vol 9(38) October 2016.

[8] J. Kennedy, R. Eberhart, "Particle swarm optimization", in: Proceedings of the IEEE International Conference on Neural Networks, Perth, Australia, pp. 1942-1948, 1995.

[9] Y. Dong et al., "An application of swarm optimization to nonlinear programming", Computer and Mathematics with Applications, Vol. 49, 1655-1668, 2005. 
[10] F. Bergh, A.P. Engelbrecht, “A study of particle swarm optimization particle trajectories”, Information Sciences, Vol. 176, pp. 937 971, 2006.

[11] M.M Shah, "A generation correlation for heat transfer during film condensation inside pipes", International Journal of Heat Mass Transfer, Vol. 22, pp. 547-556, 1979.

[12] Z. Azer et al., "Heat transfer and pressure drop during condensation inside horizontal tubes with twisted tape inserts", ASHRAE Trans, Vol. 89, pp. 96-113, 1983.

[13] M.K. Dobson, J.C. Chato, “Condensation inside smooth horizontal tubes”, ASME Journal of Heat Transfer, Vol. 120, pp. 193-212, 1998.

[14] R.W. Lockhart, R.C. Martinelli, "Proposed correlation of data for isothermal two-phase two-component flow in pipes", Chemical Engineering Progress, Vol. 45, pp. 39- 48, 1949.

[15] D. Chisholm "Pressure gradients due to friction during the flow of evaporative two-phase mixtures in smooth tubes and channels", International Journal of Heat and Mass Transfer, Vol. 16, pp. 347-358, 1973.

[16] R. Friedel, "Improved friction pressure drop correlation for horizontal and vertical two-phase pipe flow", European Two-phase Flow group Meeting, ISPRA, Italy, , paper E2, June,1979.

[17] A. Cavallini et al., "Frictional pressure drop during vapor-liquid flow in minichannels": Modeling and experimental evaluation, International Journal of Heat and Fliud flow, Vol. 30, pp. 131-138, 2009. 